\title{
Novel Electrochemical Synthesis of Polypyrrole/Ag Nanocomposite and Its Electrocatalytic Performance towards Hydrogen Peroxide Reduction
}

\author{
Ruma Gupta, ${ }^{1}$ Kavitha Jayachandran, ${ }^{1}$ J. S. Gamare, ${ }^{1}$ B. Rajeshwari, ${ }^{2}$ \\ Santosh K. Gupta, ${ }^{2}$ and J. V. Kamat ${ }^{1}$ \\ ${ }^{1}$ Fuel Chemistry Division, Bhabha Atomic Research Centre, Mumbai 400 085, India \\ ${ }^{2}$ Radiochemistry Division, Bhabha Atomic Research Centre, Mumbai 400 085, India \\ Correspondence should be addressed to Ruma Gupta; ruma.chandra@gmail.com and Santosh K. Gupta; santufrnd@gmail.com
}

Received 2 June 2015; Accepted 19 August 2015

Academic Editor: Raphael Schneider

Copyright (c) 2015 Ruma Gupta et al. This is an open access article distributed under the Creative Commons Attribution License, which permits unrestricted use, distribution, and reproduction in any medium, provided the original work is properly cited.

A simple electrochemical method of synthesis of polypyrrole/silver (PPy/Ag) nanocomposite is presented. The method is based on potentiodynamic polymerization of pyrrole followed by electrodeposition of silver employing a single potentiostatic pulse. The synthesized PPy film has embedded Ag nanocubes. The morphology and structure of the resulting nanocomposite were characterized by field emission scanning electron microscopy and X-ray diffraction. Electron paramagnetic resonance studies showed that silver nanoparticle deposition on polypyrrole leads to an increase in carrier density, indicative of enhanced conductivity of the resulting composite. Electrocatalytic performance of the prepared composite was examined for reduction of hydrogen peroxide and was compared with corresponding PPy film and bare glassy carbon electrode.

\section{Introduction}

In recent years, the electrically conducting composites have attracted attention of researchers because of their potential applications in various fields, such as sensors, actuators, and electric devices [1-4]. These include electrically conducting polymers such as polypyrrole (PPy) [5, 6], polyaniline [7-9], polythiophene [10], poly(3,4-ethylenedioxythiophene) [11], and poly(p-phenylene vinylene) [12]. PPy is known as one of the most important conducting polymers owing to its high conductivity, easy preparation, good environmental tolerance, and a large variety of applications [13]. Various nanoparticles of different metals such as $\mathrm{Au}, \mathrm{Ag}, \mathrm{Pd}, \mathrm{Cu}$, and $\mathrm{Pt}$ can be incorporated into the polymer matrix to obtain a composite material with new properties [14-17]. Chemical and electrochemical polymerizations are used to prepare conducting polymer composites. One possible way of preparation of nanocomposite material is to use a spontaneous redox reaction of monomer and metal ion, sometimes in the presence of supporting reagent [18-20]. Another one is the chemical polymerization of monomer dissolved in a solution of colloidal metal particles in the presence of an oxidant $[21,22]$. Metal nanoparticles/conducting polymer composites can also be obtained by using the electrochemical methods. These methods of preparation give a possibility of better control of the synthesis process compared to the chemical methods, because the structure, quantity, and properties of both electrodeposited components, that is, nanoparticles and polymer, depend not only on the composition of the solution, but also on the electrolysis potential and time [23, 24]. Electrochemical deposition is advantageous because of the least requirement of the additives and absence of any interfering products generated during the electrodeposition of silver metal. It is interesting to note that the deposition of Ag nanoparticles on polypyrrole film has not been attempted electrochemically so far. To the best of our knowledge, this is the first effort for the electrosynthesis of polypyrrole and then electrochemically depositing Ag nanoparticles on it. Such approach, in comparison with DC deposition, permits obtaining a more homogeneous polymer surface [25] and more homogenously distributed silver grains [26]. This necessitates the optimization of different parameters 

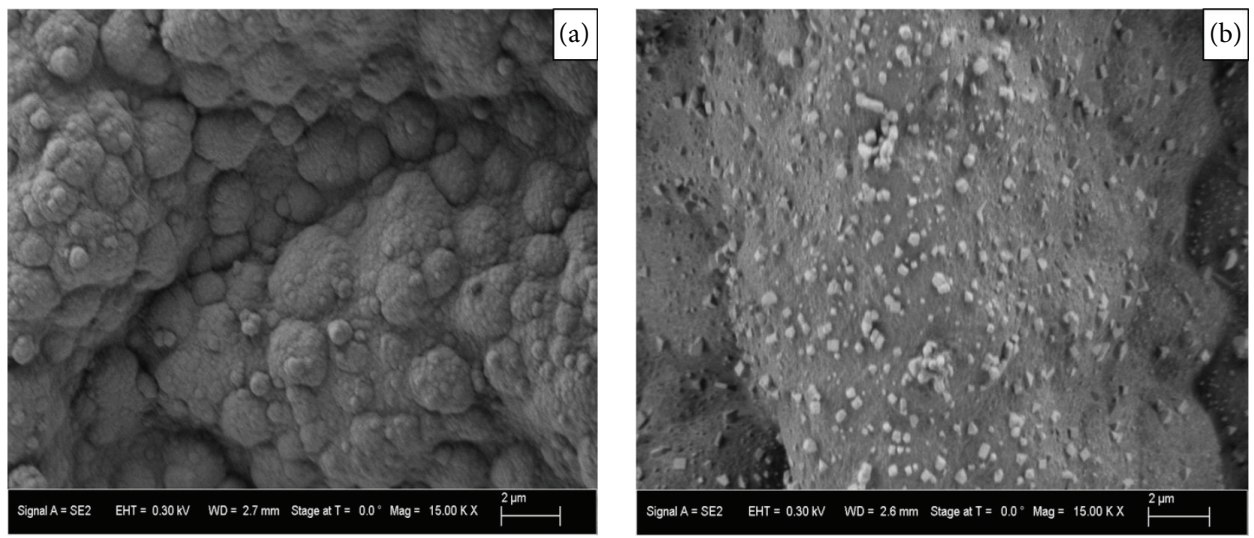

Figure 1: FESEM images of the PPy film formed by potentiodynamic growth before (a) and after (b) electrodeposition of the silver nanoparticles.

to achieve the desired quality of the polypyrrole film and silver nanoparticles. It was, therefore, of interest to develop a strategy for the electrochemical synthesis of Ag nanoparticles on a polypyrrole film and their characterization. The results of these studies are reported in this paper.

\section{Experimental}

All the chemicals, namely, pyrrole $\left(\mathrm{C}_{4} \mathrm{H}_{5} \mathrm{~N}\right)$, sulphuric acid $\left(\mathrm{H}_{2} \mathrm{SO}_{4}\right)$, potassium chloride $(\mathrm{KCl})$, silver nitrate $\left(\mathrm{AgNO}_{3}\right)$, and hydrogen peroxide $\left(\mathrm{H}_{2} \mathrm{O}_{2}\right)$, were of GR (Guaranteed Reagent) grade. Cyclic voltammetry (CV), chronoamperometry, and differential pulse voltammetry were performed using CHI 760D electrochemical workstation with a threeelectrode voltammetric cell having glassy carbon disk working electrode (area, $A=0.07 \mathrm{~cm}^{2}$ ), platinum wire counter electrode, and $\mathrm{Hg} / \mathrm{Hg}_{2} \mathrm{SO}_{4}$ reference electrode. All potentials are quoted with respect to $\mathrm{Hg} / \mathrm{Hg}_{2} \mathrm{SO}_{4}$ reference electrode. All the experiments were carried out at room temperature $\left(25 \pm 1^{\circ} \mathrm{C}\right)$. Morphology of the composite was recorded by Auriga make field emission scanning electron microscope (FESEM). X-ray diffraction (XRD) patterns were recorded in air atmosphere by STOE-Theta-X-ray diffractometer using graphite monochromatic $\mathrm{Cu} \mathrm{K} \alpha$ radiation $(\lambda=0.15406 \mathrm{~nm})$. Electron paramagnetic resonance (EPR) measurements were done at room temperature using Bruker EPR spectrometer operated at X-band frequency $(9.6 \mathrm{GHz})$. Polypyrrole (PPy) film was electrodeposited onto glassy carbon electrode by optimized procedure from aqueous $0.06 \mathrm{M}$ pyrrole solution, using $0.1 \mathrm{M} \mathrm{KCl}$ as supporting electrolyte by potentiodynamic polymerization of pyrrole. A potential sweep from $-0.9 \mathrm{~V}$ to $1 \mathrm{~V}$ was applied at a scan rate of $100 \mathrm{mV} \mathrm{s}^{-1}$ to the working electrode for a total of 30 sweep segments. $1 \mathrm{mM}$ aqueous solution of $\mathrm{AgNO}_{3}$ containing $1 \mathrm{M} \mathrm{H}_{2} \mathrm{SO}_{4}$ was used to deposit silver nanoparticles onto PPy modified working electrode by applying a fixed potential of $-0.38 \mathrm{~V}$ for 10 seconds.

\section{Results and Discussion}

Figure 1 shows FESEM images of PPy film formed by potentiodynamic growth before (a) and after (b) electrodeposition

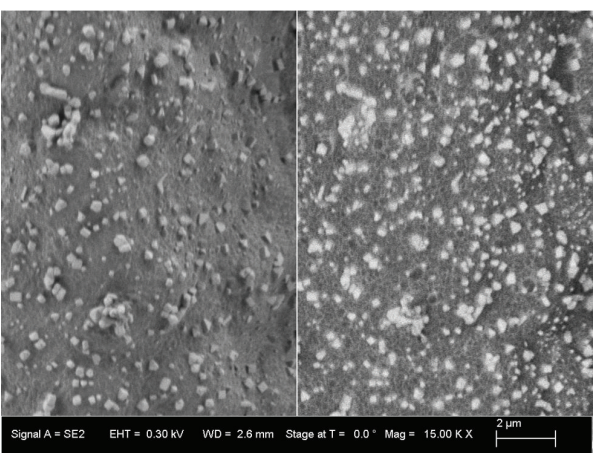

FIGURE 2: Backscattered electron image reflecting the surface composition of PPy/Ag.

TABLE 1: XRD data of silver nanoparticles $(\lambda=0.15406 \mathrm{~nm})$.

\begin{tabular}{lccccc}
\hline $2 \theta$ values & $d$ value $(\AA)$ & $I / I_{0}(\%)$ & $h$ & $k$ & $l$ \\
\hline 38.76 & 2.36 & 100 & 1 & 1 & 1 \\
44.88 & 2.04 & 44.7 & 2 & 0 & 0 \\
65.11 & 1.44 & 22.3 & 2 & 2 & 0 \\
77.87 & 1.23 & 22.0 & 3 & $\mathbf{1}$ & $\mathbf{1}$ \\
81.86 & 1.17 & 6.0 & 2 & 2 & 2 \\
\hline
\end{tabular}

of silver nanoparticles. The polymer exhibits the typical cauliflower-like nodular morphology. More changes in the structure and surface composition of the PPy/Ag could be noticed by using SEM backscattered electron detector (Figure 2). The contrast visible in the images reflects the surface composition of the material. The bright objects correspond to the positions where the silver structures are present, and the dark area is related to the polypyrrole matrix. Powder XRD pattern shown in Figure 3 also confirmed the presence of silver in the nanocomposites. All the diffraction peaks could be indexed to the cubic phase of silver (JCPDS card number 87-0717) having fcc lattice. The crystallographic data of the relatively intense peak $\left(I / I_{0}>5\right)$ was indexed on a cubic system with space group $\mathrm{Fm}-3 \mathrm{~m}$ and cell parameter $a=4.085 \AA$. The XRD data are given in Table 1. 


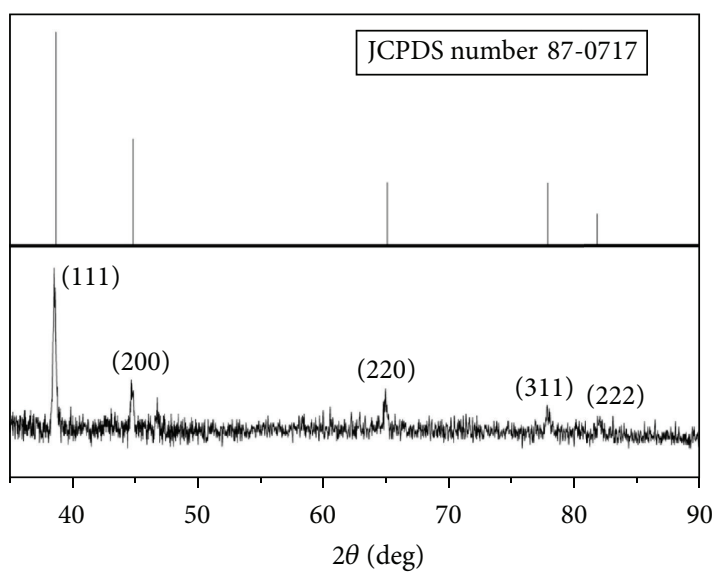

FIGURE 3: XRD pattern of silver nanoparticles.
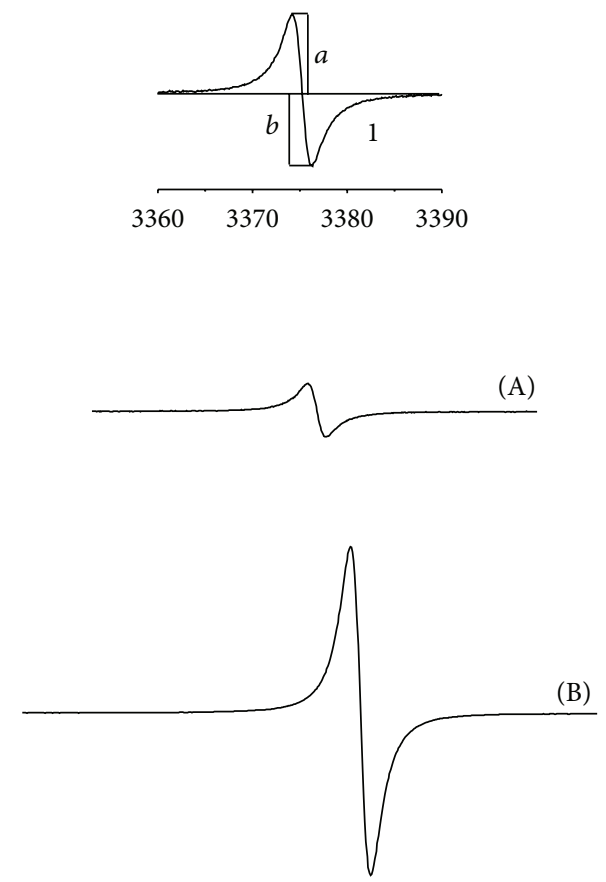

\begin{tabular}{cccccc}
\hline 3350 & 3360 & 3370 & 3380 & 3390 & 3400 \\
& $H$ (Gauss)
\end{tabular}

FIGURE 4: EPR spectra recorded at room temperature at X-band frequency $(9.5 \mathrm{GHz})$ using receiver gain $\mathrm{RG}=2.5 \times 10^{3}$; modulation amplitude $\mathrm{MA}=1.0 \mathrm{G}$; microwave power $6.3 \mathrm{~mW}$. (A) Polypyrrole (PPy) polymer and (B) Ag/PPy composite. (1) shows the asymmetrical signal in PPy polymer with $a / b=1.4$ (Dysonian line shape).

EPR spectrum of PPy (Figure 4(A)) showed a single Lorentzian line with a slight asymmetry \{Dysonian line shape, asymmetry parameter $a / b=1.4$ as shown in Figure $4(1)\}$ at $g=2.0026$ indicating the presence of polaron (charge carrier with spin $1 / 2$ due to unpaired electron). This value is close to the free electron $g$ value $(g=2.0023)$. The small increase in $g$ value observed for PPy/Ag indicates that the unpaired electrons are present in the $\pi$ electron system for

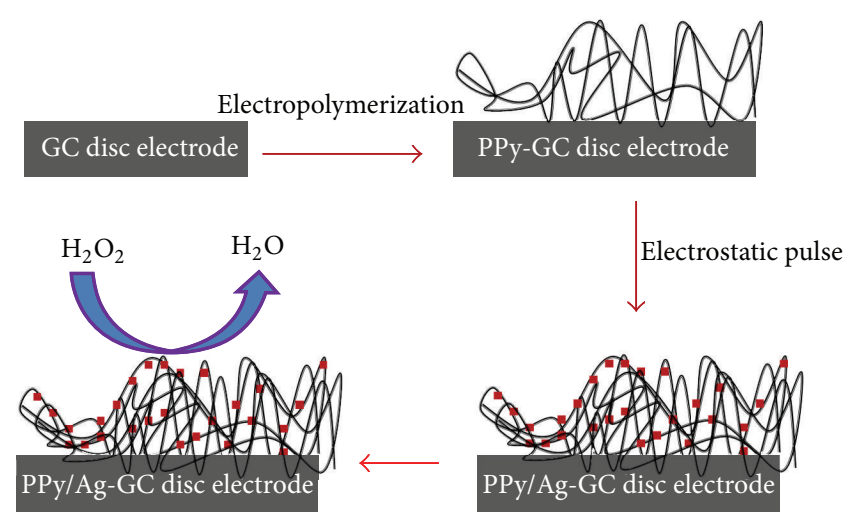

FIGURE 5: Schematic diagram of electrode modification process with polypyrrole and silver nanoparticles and its electrocatalytic application for hydrogen peroxide reduction.

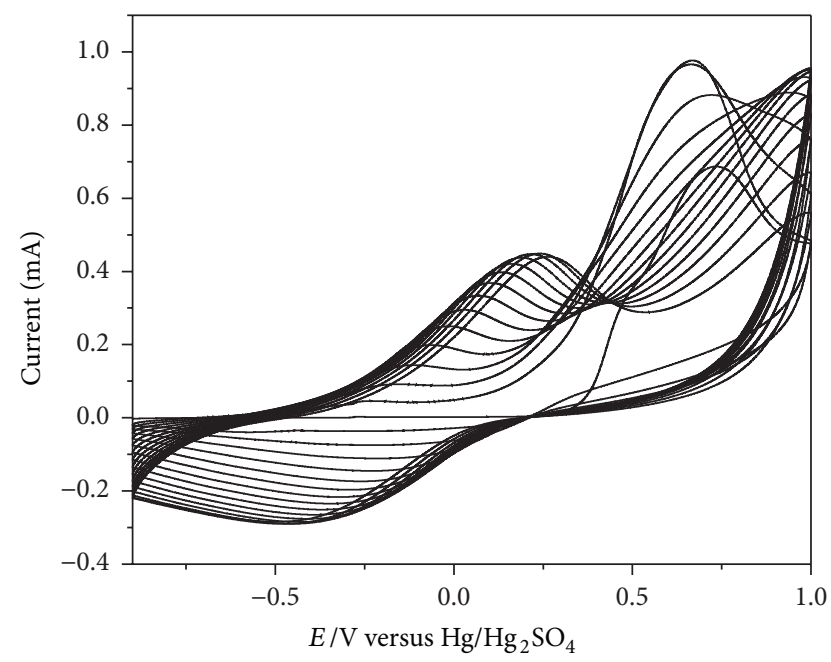

Figure 6: Cyclic voltammograms obtained during the potentiodynamic growth of PPy on a $3 \mathrm{~mm}$ diameter glassy carbon disc electrode. The potential was swept from $-0.9 \mathrm{~V}$ to $1 \mathrm{~V}$ versus $\mathrm{Hg} / \mathrm{Hg}_{2} \mathrm{SO}_{4} 15$ cycles at $100 \mathrm{mV} \mathrm{s}^{-1}$.

the conjugated polymers [27]. Upon electrodepositing silver on polymer matrix, the EPR signal became more symmetric $(a / b=1.0)$. It was observed that Ag deposition leads to a corresponding increase in the area under the peak computed by double integration of the signal. This proves an increase in carrier density of the composite which is responsible for enhancement of catalytic activity [28]. Figure 5 shows the schematic diagram of electrode modification process with polypyrrole and silver nanoparticles and its electrocatalytic application for hydrogen peroxide reduction.

Cyclic voltammetry (CV) was employed to monitor the polymerization of PPy and to investigate the kinetics of electrode process for electropolymerization. Figure 6 shows the first 15 cyclic voltammograms obtained during the potentiodynamic growth of PPy on a $3 \mathrm{~mm}$ diameter GC disc electrode as the potential was swept from $-0.9 \mathrm{~V}$ to $1 \mathrm{~V}$. The cathodic peaks obtained were significantly broader than the anodic peaks. The voltammograms are consistent with those 


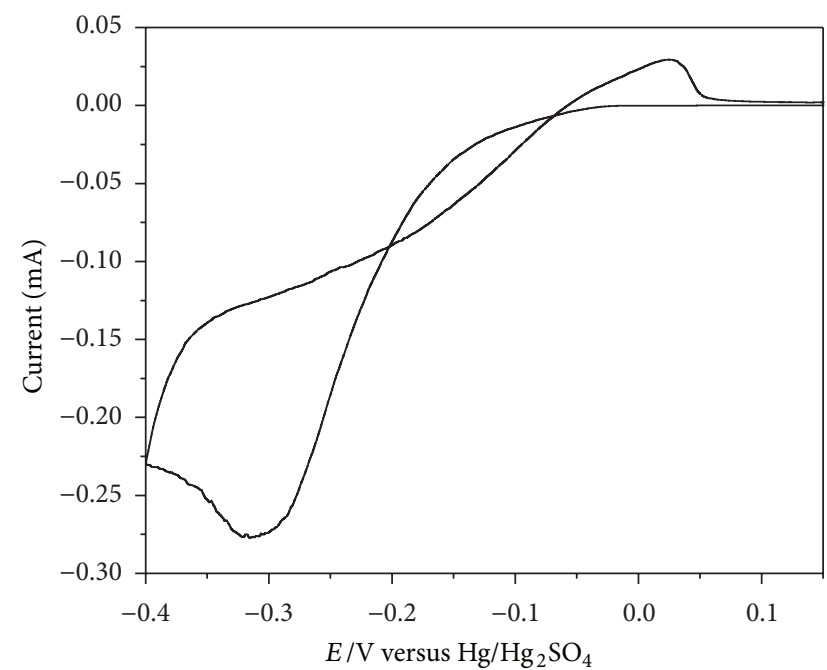

(a)

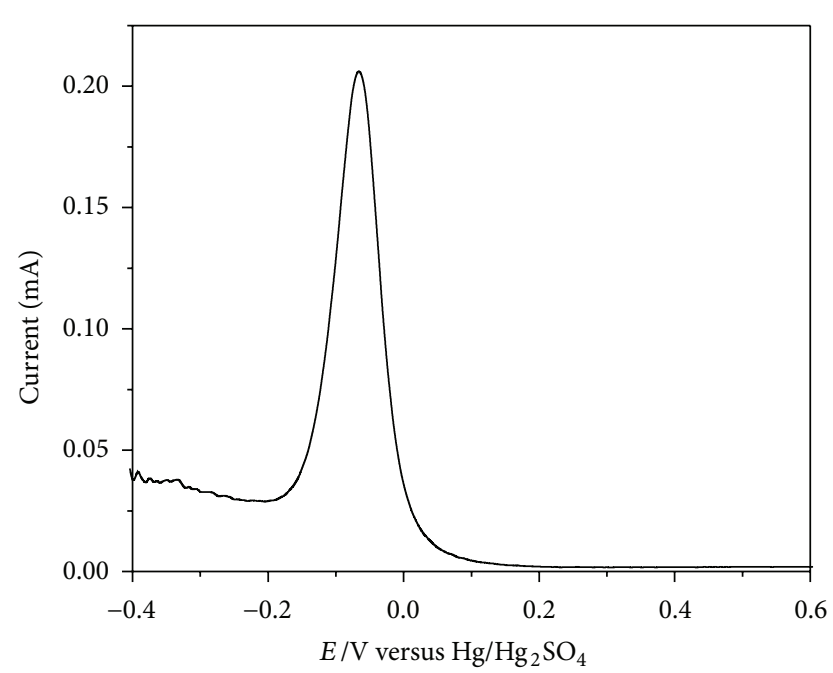

(b)

Figure 7: (a) Cyclic voltammogram of $1 \mathrm{mM}$ aqueous solution of $\mathrm{AgNO}_{3}$ containing $1 \mathrm{M} \mathrm{H}_{2} \mathrm{SO}_{4}$ at $\mathrm{PPy}$ modified electrode. (b) Differential pulse voltammogram carried out with $\mathrm{PPy} / \mathrm{Ag}$ composite electrode in $1 \mathrm{M} \mathrm{H}_{2} \mathrm{SO}_{4}$.

reported previously [29]. On the first scan, a single anodic wave was typically observed at approximately $+0.5 \mathrm{~V}$ which is consistent with the oxidation of pyrrole monomer to produce the radical cation [30]. On the second scan and all the subsequent oxidative scans, a new anodic wave is observed that is consistent with the oxidation of the newly formed polymer between $-0.1 \mathrm{~V}$ and $0.5 \mathrm{~V}[29,30]$. With each successive scan, the peak current associated with the anodic as well as the cathodic peaks of the polymer increased and an increasingly thick, dark black coloured film was observed on the working electrode. The increase in charge passed between each cycle was approximately constant suggesting that the growth rate of the polymer is approximately constant. Depositing silver nanoparticles within the PPy film provides a convenient way to increase the area available for the electrocatalysis to take place and may improve the film conductivity.

Figure 7(a) shows $\mathrm{CV}$ of $1 \mathrm{mM}$ aqueous solution of $\mathrm{AgNO}_{3}$ containing $1 \mathrm{M} \mathrm{H}_{2} \mathrm{SO}_{4}$ at PPy modified electrode. Based on the $\mathrm{CV}$ results, $-0.38 \mathrm{~V}$ was chosen as the optimized potential to deposit silver nanoparticles. Differential pulse voltammogram (DPV) shown in Figure $7(\mathrm{~b})$ was obtained with $\mathrm{PPy} / \mathrm{Ag}$ composite electrode in $1 \mathrm{M} \mathrm{H}_{2} \mathrm{SO}_{4}$. The anodic peak observed at $-0.068 \mathrm{~V}$ is responsible for the stripping of $\mathrm{Ag}^{+}$from metallic $\mathrm{Ag}$ nanoparticles. This further confirmed the presence of $\mathrm{Ag}$ at polypyrrole matrix.

The electrochemical behavior of the synthesized PPy and PPy/Ag was examined by cyclic voltammetry to catalyse reduction of hydrogen peroxide. Figure 8 shows the cyclic voltammograms of bare-GC, PPy-GC, and PPy/AgGC coated electrodes in presence of $0.4 \mathrm{mM} \mathrm{H}_{2} \mathrm{O}_{2}$ in $1 \mathrm{M}$ $\mathrm{H}_{2} \mathrm{SO}_{4}$. It is clearly seen that when bare glassy carbon electrode was used, no well-defined peak with very small current was observed in presence of $\mathrm{H}_{2} \mathrm{O}_{2}$. For PPy-GC electrode, although the current was high enough no substantial peak was seen for the reduction of hydrogen peroxide.

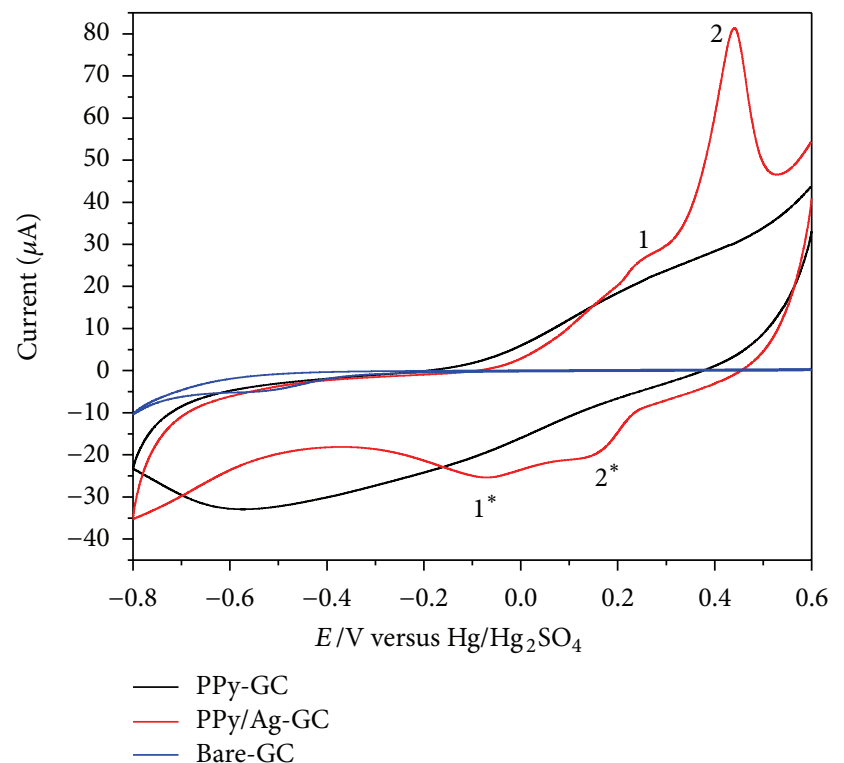

Figure 8: Cyclic voltammograms using bare-GC, PPy-GC, and $\mathrm{PPy} / \mathrm{Ag}-\mathrm{GC}$ electrodes in presence of $0.4 \mathrm{mM} \mathrm{H}_{2} \mathrm{O}_{2}$ in $1 \mathrm{M} \mathrm{H}_{2} \mathrm{SO}_{4}$.

Only a broad cathodic peak was observed between $-0.5 \mathrm{~V}$ and $-0.6 \mathrm{~V}$. When silver nanoparticles were embedded in polypyrrole film (PPy/Ag), the silver modified PPy film electrode exhibited a considerable electrocatalytic behaviour towards the reduction of hydrogen peroxide and a reduction peak appeared at about $-0.08 \mathrm{~V}\left(1^{*}\right)$ versus $\mathrm{Hg} / \mathrm{Hg}_{2} \mathrm{SO}_{4}$ reference electrode. Another cathodic peak at around $0.2 \mathrm{~V}$ $\left(2^{*}\right)$ was attributed to the reduction of AgOH in the PPy film. Typically, this reduction is preceded by uptake of $\mathrm{H}^{+}$ions during reduction of $\mathrm{PPy}$. We can conclude that, after addition of hydrogen peroxide to the solution, silver dispersed in the 
PPy film reacts chemically with hydrogen peroxide according to the following equation [31]:

Step 1

$$
2 \mathrm{PPy} / \mathrm{Ag}(0)+\mathrm{H}_{2} \mathrm{O}_{2} \longrightarrow 2 \mathrm{PPy}-\mathrm{Ag}(\mathrm{I})-\mathrm{OH}
$$

The second step is electrochemical reduction of silver hydroxide $\left(\right.$ peak $\left.2^{*}\right)$ :

Step 2

$$
\begin{gathered}
2 \mathrm{PPy} \text { Ag }(\mathrm{I})-\mathrm{OH}+2 \mathrm{H}^{+}+2 \mathrm{e}^{-} \\
\longrightarrow 2 \mathrm{PPy} \mathrm{Ag}(0)+2 \mathrm{H}_{2} \mathrm{O}
\end{gathered}
$$

The peak present at $0.5 \mathrm{~V}$ is attributed to $\mathrm{AgO}$ stripping peak (2).

\section{Conclusion}

Fabrication of PPy/Ag composite through electrosynthesis of polypyrrole and then electrochemically depositing Ag nanoparticles is presented. Such approach, in comparison with DC deposition, permits obtaining a more homogeneous polymer surface and more homogenously distributed silver grains. FESEM, XRD, and electrochemical measurements indicate that $\mathrm{Ag} /$ polypyrrole nanocomposite is successfully prepared in our experiments. This further showed electrocatalytic performance towards hydrogen peroxide reduction. We believe that the present method could be exploited for the fabrication of novel and inexpensive hydrogen peroxide sensor.

\section{Conflict of Interests}

The authors declare that there is no conflict of interests regarding the publication of this paper.

\section{Acknowledgments}

The authors sincerely thank Dr. C. B. Basak of Glass and Advanced Ceramic Division, BARC, and Dr. Meera Keskar, Fuel Chemistry Division, BARC, for experimental support.

\section{References}

[1] S. B. Wang and G. Q. Shi, "Uniform silver/polypyrrole core-shell nanoparticles synthesized by hydrothermal reaction," Materials Chemistry and Physics, vol. 102, no. 2-3, pp. 255-259, 2007.

[2] A. H. Chen, H. Q. Wang, B. X. Zhao, and Y. Li, "The preparation of polypyrrole- $\mathrm{Fe}_{3} \mathrm{O}_{4}$ nanocomposites by the use of common ion effect," Synthetic Metals, vol. 139, no. 2, pp. 411-415, 2003.

[3] A. Alqudami, S. Annapoorni, P. Sen, and R. S. Rawat, "The incorporation of silver nanoparticles into polypyrrole: conductivity changes," Synthetic Metals, vol. 157, no. 1, pp. 53-59, 2007.

[4] H. Y. Li, H. Wang, A. H. Chen, B. Meng, and X. Li, "Ordered macroporous titania photonic balls by micrometer-scale spherical assembly templating," Journal of Materials Chemistry, vol. 15 , no. 26, article 2551, 2005.
[5] S. Sadki, P. Schottland, N. Brodie, and G. Sabouraud, "The mechanisms of pyrrole electropolymerization," Chemical Society Reviews, vol. 29, no. 5, pp. 283-293, 2000.

[6] F. Yan, G. Xue, and M. Zhou, "Preparation of electrically conducting polypyrrole in oil/water microemulsion," Journal of Applied Polymer Science, vol. 77, no. 1, pp. 135-140, 2000.

[7] D. Kim, J. Choi, J.-Y. Kim, Y.-K. Han, and D. Sohn, "Size control of polyaniline nanoparticle by polymer surfactant," Macromolecules, vol. 35, no. 13, pp. 5314-5316, 2002.

[8] D. Han, Y. Chu, L. Yang, Y. Liu, and Z. Lv, "Reversed micelle polymerization: a new route for the synthesis of DBSApolyaniline nanoparticles," Colloids and Surfaces A: Physicochemical and Engineering Aspects, vol. 259, no. 1-3, pp. 179-187, 2005.

[9] H. Gao, T. Jiang, B. Han et al., "Aqueous/ionic liquid interfacial polymerization for preparing polyaniline nanoparticles," Polymer, vol. 45, no. 9, pp. 3017-3019, 2004.

[10] R. D. McCullough, "The chemistry of conducting polythiophenes," Advanced Materials, vol. 10, no. 2, pp. 93-116, 1998.

[11] S. Kirchmeyer and K. J. Reuter, "Scientific importance, properties and growing applications of poly (3,4-ethylenedioxythiophene)," Journal of Materials Chemistry, vol. 15, no. 21, pp. $2077-$ 2088, 2005

[12] H. Skaff, K. Sill, and T. J. Emrick, "Quantum dots tailored with poly(para-phenylene vinylene)," Journal of the American Chemical Society, vol. 126, no. 36, pp. 11322-11325, 2004.

[13] J. Jang, J. H. Oh, and G. D. Stucky, "Fabrication of ultrafine conducting polymer and graphite nanoparticles," Angewandte Chemie International Edition, vol. 41, no. 21, pp. 4016-4019, 2002.

[14] R. Gangopadhyay and A. De, "Conducting polymer nanocomposites: a brief overview," Chemistry of Materials, vol. 12, no. 3, pp. 608-622, 2000.

[15] K. Jlassi, A. Singh, D. K. Aswal, R. Losno, M. Benna-Zayani, and M. M. Chehimi, "Novel, ternary clay/polypyrrole/silver hybrid materials through in situ photopolymerization," Colloids and Surfaces A: Physicochemical and Engineering Aspects, vol. 439, pp. 193-199, 2013.

[16] M. F. Attia, T. Azib, Z. Salmi et al., "One-step UV-induced modification of cellulose fabrics by polypyrrole/silver nanocomposite films," Journal of Colloid and Interface Science, vol. 393, no. 1, pp. 130-137, 2013.

[17] S. Fujii, S. Matsuzawa, Y. Nakamura et al., "Synthesis and characterization of polypyrrole-palladium nanocomposite-coated latex particles and their use as a catalyst for suzuki coupling reaction in aqueous media," Langmuir, vol. 26, no. 9, pp. 6230$6239,2010$.

[18] S. Wang and G. Shi, "Uniform silver/polypyrrole core-shell nanoparticles synthesized by hydrothermal reaction," Materials Chemistry and Physics, vol. 102, no. 2-3, pp. 255-259, 2007.

[19] T. Selvan, J. P. Spatz, H. Klok, and M. Möller, "Gold-polypyrrole core-shell particles in diblock copolymer micelles," Advanced Materials, vol. 10, no. 2, pp. 132-134, 1998.

[20] A. Chen, H. Wang, and X. Li, "One-step process to fabricate Agpolypyrrole coaxial nanocables," Chemical Communications, vol. 14, pp. 1863-1864, 2005.

[21] S. Jing, S. Xing, L. Yu, and C. Zhao, "Synthesis and characterization of Ag/polypyrrole nanocomposites based on silver nanoparticles colloid," Materials Letters, vol. 61, no. 23-24, pp. 4528-4530, 2007. 
[22] H. J. Shin, I.-W. Hwang, Y.-N. Hwang et al., "Comparative investigation of energy relaxation dynamics of gold nanoparticles and gold-polypyrrole encapsulated nanoparticles," Journal of Physical Chemistry B, vol. 107, no. 20, pp. 4699-4704, 2003.

[23] N. F. Heinig, N. Kharbanda, M. R. Pynenburg, X. J. Zhou, G. A. Schultz, and K. T. Leung, "The growth of nickel nanoparticles on conductive polymer composite electrodes," Materials Letters, vol. 62, no. 15, pp. 2285-2288, 2008.

[24] D. A. Kaplin and S. Qutubuddin, "Electrochemically synthesized polypyrrole films: effects of polymerization potential and electrolyte type," Polymer, vol. 36, no. 6, pp. 1275-1286, 1995.

[25] R. K. Sharma, A. C. Rastogi, and S. B. Desu, "Pulse polymerized polypyrrole electrodes for high energy density electrochemical supercapacitor," Electrochemistry Communications, vol. 10, no. 2, pp. 268-272, 2008.

[26] Z. Rakočević, S. Štrbac, D. Peruško, N. Bibić, and T. Nenadović, "Pulse deposition of Au on graphite," Thin Solid Films, vol. 288, no. 1-2, pp. 212-216, 1996.

[27] C. E. Lee, D. K. Oh, J.-I. Jin, and B.-K. Nam, "EPR study of the PPV conducting polymers," Synthetic Metals, vol. 69, no. 1-3, pp. 425-426, 1995.

[28] L. D. Kispert, J. Joseph, G. G. Miller, and R. H. Baughman, "EPR study of polarons in a conducting polymer with nondegenerate ground states: alkali metal complexes of poly (p-phenylene) and phenylene oligomers," The Journal of Chemical Physics, vol. 81, no. 4, pp. 2119-2125, 1984.

[29] Y. Tezuka, K. Aoki, H. Yajima, and T. Ishii, "Concentration profiles of conducting species in polypyrrole films in cyclic voltammetry by means of a diode array detector," Journal of Electroanalytical Chemistry, vol. 425, no. 1-2, pp. 167-172, 1997.

[30] P. A. Mabrouk, "Oxidative electropolymerization of pyrrole from neat monomer solution," Synthetic Metals, vol. 150, no. 1, pp. 101-105, 2005.

[31] F. T. Maggs and D. Sutton, "Some aspects of the catalytic decomposition of concentrated hydrogen peroxide by silver. Part 1.- the solubility and rate of solution of silver," Transactions of the Faraday Society, vol. 54, pp. 1861-1870, 1958. 

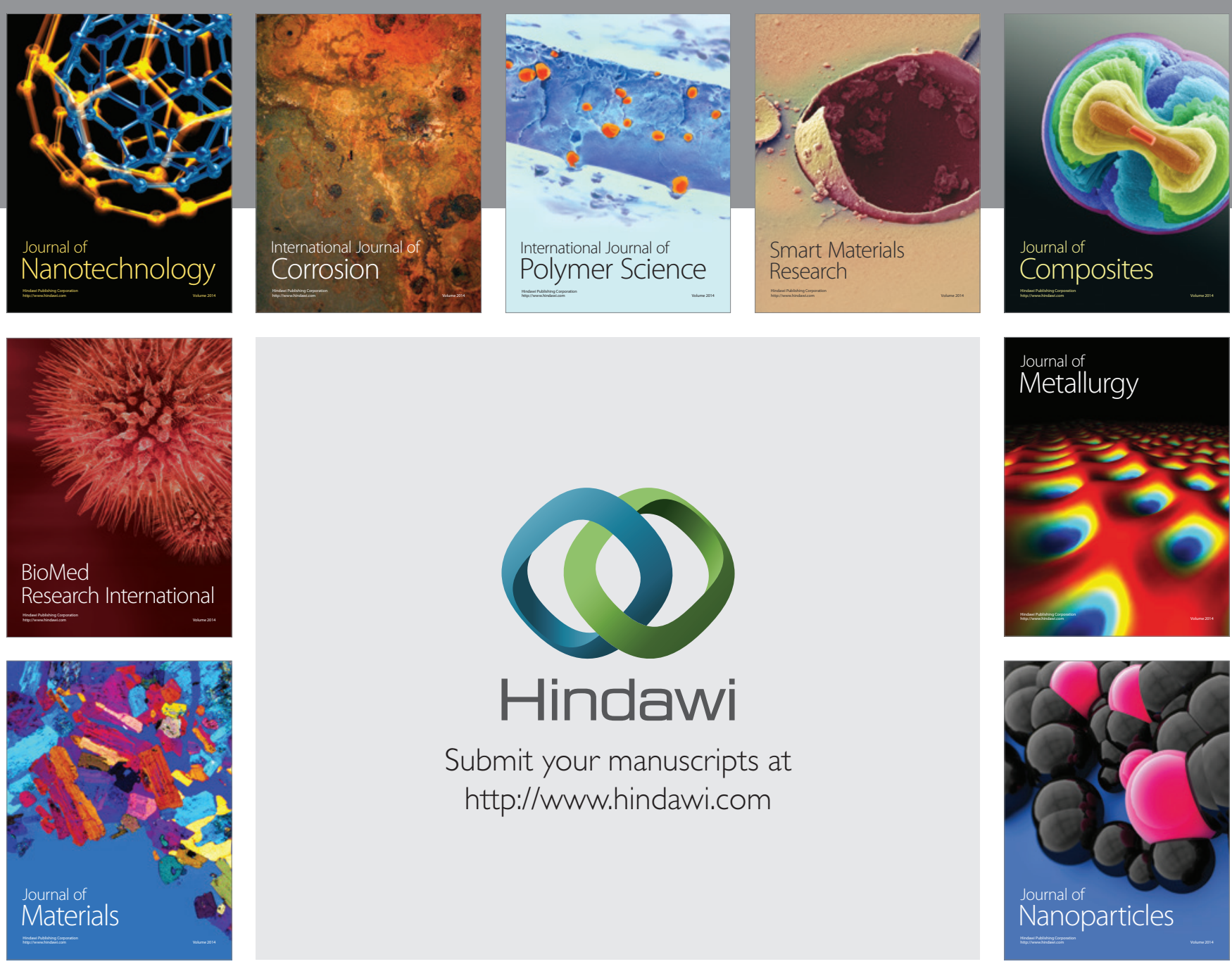

Submit your manuscripts at http://www.hindawi.com
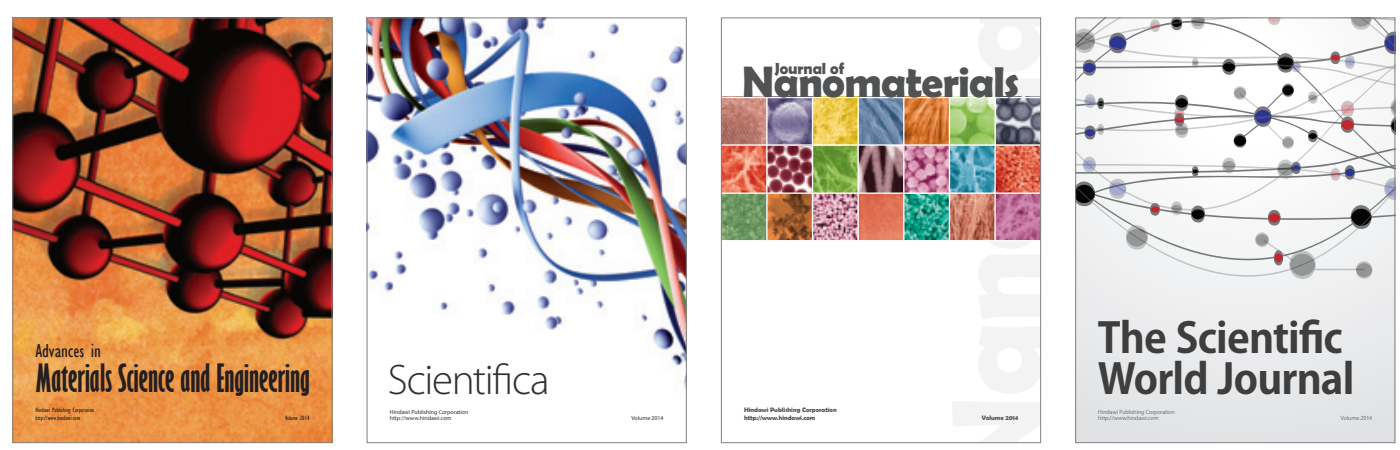

\section{The Scientific World Journal}
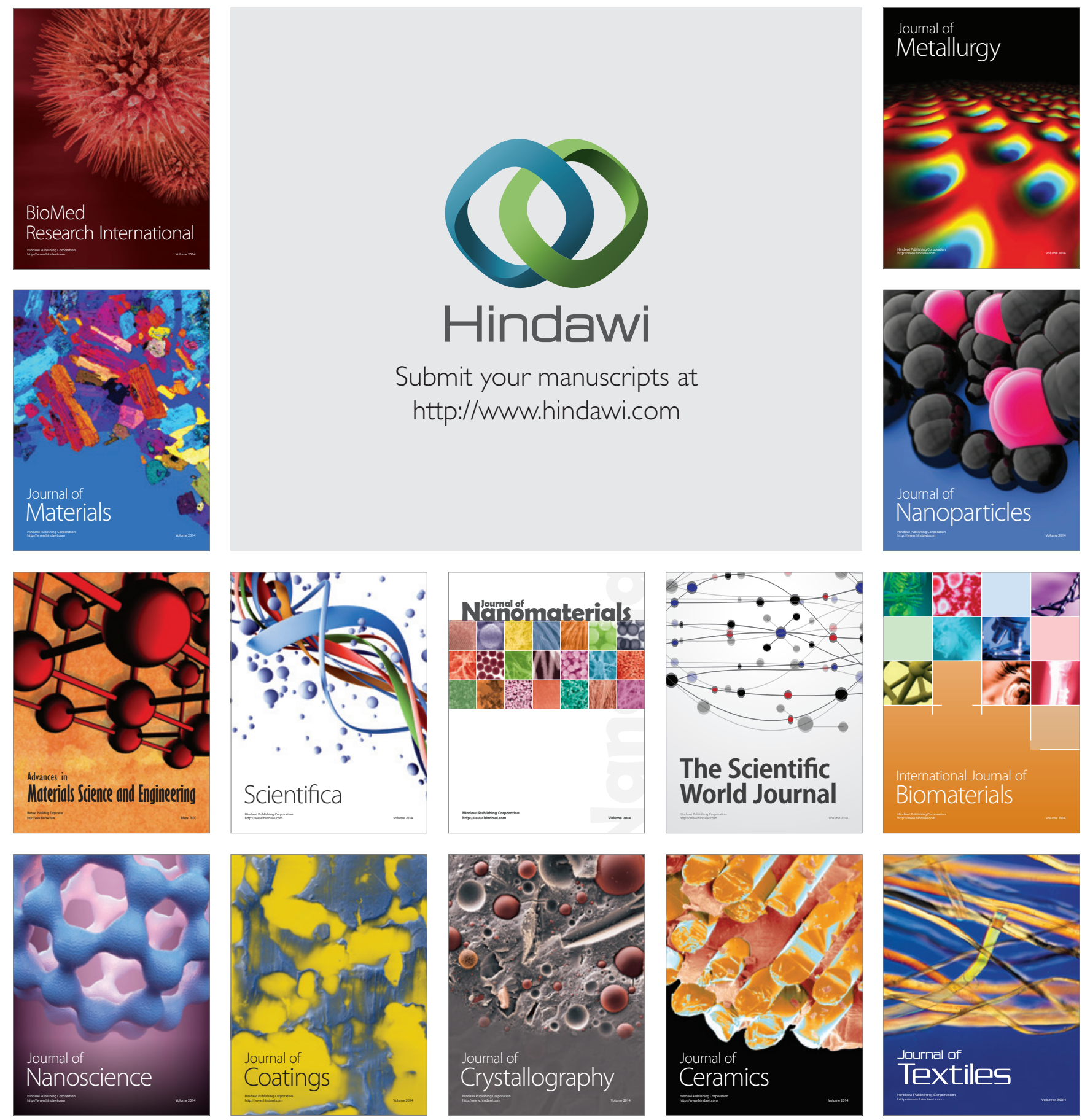